\title{
A Program in Refractory Metal Thermocouple Research*
}

\author{
G. W. Burns and W. S. Hurst \\ Institute for Basic Standards, National Bureau of Standards, Washington, D.C. 20234
}

(February 8, 1971)

\begin{abstract}
A refractory metal thermocouple research program, directed towards establishing the parameters that are necessary to achieve reliable, long term, high temperature thermocouple performance, is outlined. A description of special apparatus for exposing bare-wire thermoelements to high temperatures in vacuum and in high purity gaseous environments is given, and the design and performance of an ultra-high-vacuum, high-temperature furnace system are described. Bare-wire W-3 percent Re and W-25 percent Re thermoelements were exposed at $2400 \mathrm{~K}$ in argon, hydrogen or vacuum, and experienced a shift in their emf-temperature relationship upon initial exposure. After the initial shift, the thermoelements exposed in the gaseous environments experienced no significant further change in their emf-temperature relationship for periods up to 1000 hours. The thermoelements exposed in vacuum continually drifted in their emf-temperature relationship as a result of the preferential loss of Re by evaporation.
\end{abstract}

Key words: EMF-temperature relationship; furnace; high temperature; refractory metals; thermocouple; thermoelements; sensor; ultra high vacuum; W-Re alloys.

\section{Introduction}

The temperature measuring systems required in the technology of nuclear power systems and energy conversion devices have resulted in increased demands on the capabilities of high temperature thermocouple sensors. In particular, the design and development of propulsion and space power systems are requiring reliable thermocouple sensor operation at temperatures between 1800 and $2400 \mathrm{~K}$ for thousands of hours. Almost without exception, ceramic insulated, metal sheathed, W-Re thermocouple type sensors of various designs are employed in these applications.

However, for commercial thermocouple sensors currently available, the experience has been that thermocouple reliability for extended periods is generally unpredictable, even in relatively low temperature, non-nuclear environments $[1,2,3] .{ }^{1}$ For example, Sandefur et al. [1] report that W-Re type thermocouple sensors used in irradiation capsules sometimes lasted throughout the irradiation, whereas at other times, under exactly the same conditions, supposedly identical sensors failed at the beginning of irradiation.

It is reasonable to expect that the performance and reliability of thermocouple sensors could be improved by exercising more care in their design and construction. Some substantial improvements might be realized through more careful selection, processing, and handling of materials, inasmuch as previous studies $[4,5]$ have already shown that small amounts of impurities may greatly influence the performance of W-Re type thermocouples. Thermodynamic consideration of the chemical stability of

* Work supported by NASA.Lewis Research Center, under Interagency Agreement, NASA Order Numbers C-30968-B and C-61545-B.

${ }^{1}$ Figures in brackets indicate the literature references at the end of this paper. materials commonly used in configuring high temperature thermocouple sensors indicate that if gaseous reaction products are confined and materials are pure, little chemical reaction will take place $[4]$. Thus, reasonable thermoelectric stability should occur in non-nuclear environments if the thermocouple materials are sufficiently pure and the thermocouple sheath maintains the necessary integrity. Furthermore, some of the failures in presently available sensors are of a mechanical nature, and often occur during the first few hours of use. These failures result from such effects as gas leakage at thermocouple sheath seals, cracked sheaths, and breakage of the thermocouple hot junction upon initial heating. With improved fabrication techniques, it should be possible to reduce the failure rate from this cause.

Accordingly, a new refractory metal thermocouple research program was initiated at the National Bureau of Standards and is directed towards establishing those parameters that are necessary to achieve reliable, long term thermocouple sensor performance. An investigation with carefully processed and well characterized materials in controlled environments has been undertaken to accomplish this objective.

For this program the sensor materials have been limited to W-Re alloy thermoelements, high purity sintered beryllium oxide $(\mathrm{BeO})$ insulators, and Ta or W-Re alloy sheaths. The studies have been confined to thermoelements of $0.25 \mathrm{~mm}$ diam or less and sheaths with $1.6 \mathrm{~mm}$ o.d. or less. The experimental approach has been to study first the performance of each component of the sensor separately, then in a two component interaction, and finally as a complete assembly. Thus, extensive studies were first performed to investigate the behavior of barewire (noninsulated) thermoelements in various gaseous 
environments and in vacuum. Studies were then begun with $\mathrm{BeO}$-insulated thermoelements in these same environments. Yet to be performed are sheath evaluation, $\mathrm{BeO}$ sheath interaction studies, and finally, evaluation of the performance of completely assembled thermocouple sensors. The temperature range of interest has been 2000 to $2400 \mathrm{~K}$, although bare wire studies have been extended to as high as $3000 \mathrm{~K}$. This paper describes the experimental techniques and apparatus being used in the program, and presents a few of the preliminary results that have been obtained.

\section{Test Apparatus and Procedures}

\subsection{Studies of Bare-Wire Thermoelements}

A typical apparatus for exposing bare-wire thermoelements at high temperatures in a gaseous environment or in vacuum is illustrated in figure 1 . Four units of similar design are used for this purpose. The unit illustrated consists of a double-wall, water-cooled stainless steel chamber,

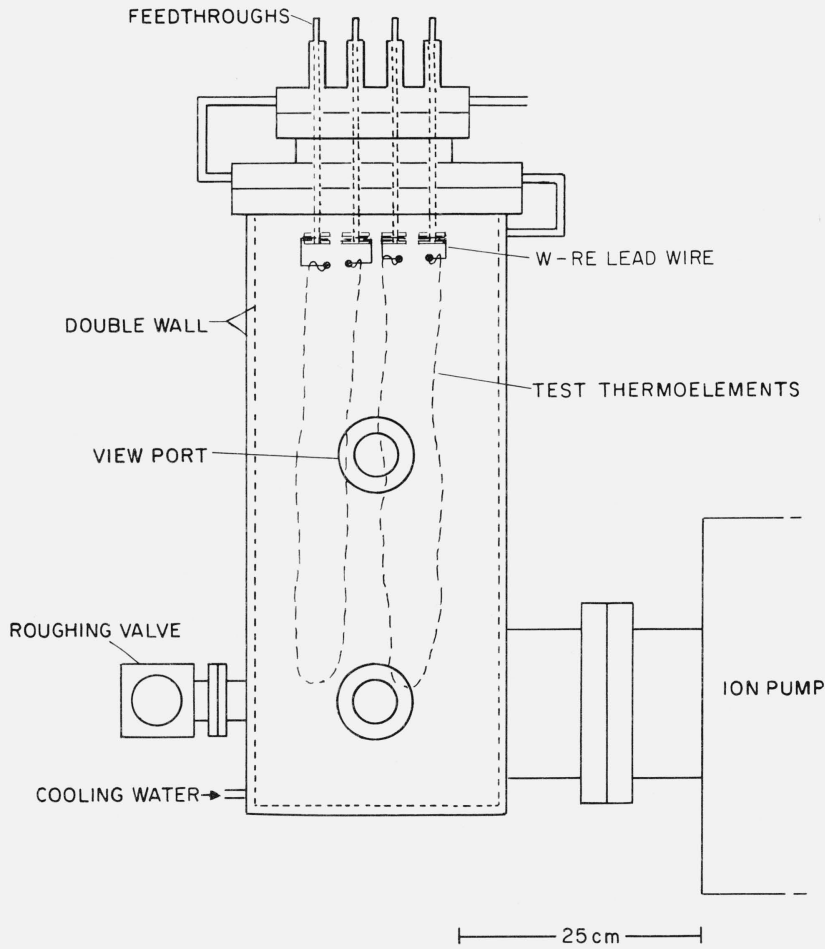

Figure 1. Test chamber for thermal exposure of bare-wire thermoelements.

The $1 \mathrm{~cm}$ all-metal valve, gas manifold and ionization gage are not shown.

$25 \mathrm{~cm}$ in diameter by $65 \mathrm{~cm}$ high. Several ports are provided, equipped with standard ultra-high-vacuum-type flanges that seal with copper gaskets. At the top of the chamber, a special $30 \mathrm{~cm}$ diam water-cooled flange, equipped with a $15 \mathrm{~cm}$ diam access port, is sealed with a gold O-ring to a mating flange on the chamber. From 12 to 16 metal-to-ceramic sealed electrical feedthroughs are provided on the water-cooled flange installed on the access port. Mounted on $3.8 \mathrm{~cm}$ diam ports around the lower portion of the chamber are a $2.5 \mathrm{~cm}$ bakeable allmetal valve for roughing of the system, a Bayard-Alpert type ionization gage, and a $1 \mathrm{~cm}$ bakeable all-metal valve that is connected to a $1 \mathrm{~cm}$ diam stainless steel gas manifold. A Corning ${ }^{2}$ type 7056 glass window is provided on the centrally located $3.8 \mathrm{~cm}$ diam port. Connected to the chamber by a $15 \mathrm{~cm}$ diam port is a 200 liter/s ion pump.

To create the desired test environments, the chamber is first evacuated to a pressure in the $10^{-3}$ torr $^{3}$ range with molecular sieve sorption pumps. Then, with ion pumping, pressures of $5 \times 10^{-9}$ torr and lower are achieved within $24 \mathrm{~h}$, following a mild bakeout of the chamber and ion pump at about $400 \mathrm{~K}$. Static gas environments are obtained by backfilling the evacuated test chamber to about 1 atm pressure from a cylinder of high purity compressed gas through the stainless steel gas manifold. A stainless steel gas transfer regulator and a stainless steel Bourdon tube gage are included in the manifold to facilitate gas pressure regulation. For tests in vacuum, the pressure is maintained at less than $1 \times 10^{-8}$ torr with the thermoelements at test temperature.

The test thermoelements, which are usually 90 to 100 $\mathrm{cm}$ in length, are hung vertically within the chamber from the electrodes, as shown in figure 1. They are welded to a short length of $0.5 \mathrm{~mm}$ diameter lead wire of nominally the same alloy, and the lead wire is then clamped between copper washers on the electrode. The thermoelements are cleaned with ether and during the mounting operation are handled using polyethylene gloves. As many as six thermoelements are mounted in the chamber and tested at the same time. During high temperature exposure tests, the thermoelements are heated electrically with alternating current $(60$ hertz). The current to each thermoelement is adjusted separately by manual regulation of a solid-state A-C current controller. The temperature of each thermoelement is determined and monitored during the exposure with a calibrated ${ }^{4}$ visual optical pyrometer. Corrections are applied to account for the spectral transmittance of the glass window on the chamber and the spectral emittance of the thermoelements.

After exposure for specified periods of time, the test thermoelements are removed from the chamber and measurements are made of their thermal emf versus an unheated "as received" thermoelement from the same spool (lot) of wire. Measurements are typically made at $200 \mathrm{~K}$ intervals from 673 to $2073 \mathrm{~K}$ by heating the samples in argon in a high temperature resistance heated furnace [6]. For these tests, the temperature is determined with a $\mathrm{W}-3$ percent Re versus $\mathrm{W}-25$ percent Re thermocouple, with an estimated uncertainty in the temperature measurement of not more than \pm 0.5 percent. In all tests the temperature of the reference junctions is maintained at $273.15 \mathrm{~K}$ in an ice bath, and the values of thermal emf are measured with a precision potentiometer having a resolution of $0.1 \mu \mathrm{V}$ and a limit of error of not more than $\pm(0.015$ percent of reading $+0.5 \mu \mathrm{V})$.

This procedure yields the relative changes in the thermal

2 A trade name is identified in this paper in order to adequately specify the experimental procedure. Such identification does not imply recommendation or indorsement by the National Bureau of Standards.

3 One torr $=133.322$ newtons per square meter.

4 Calibration performed by Radiation Thermometry Section at NBS. See NBS Monograph 41 for calibration procedure. 


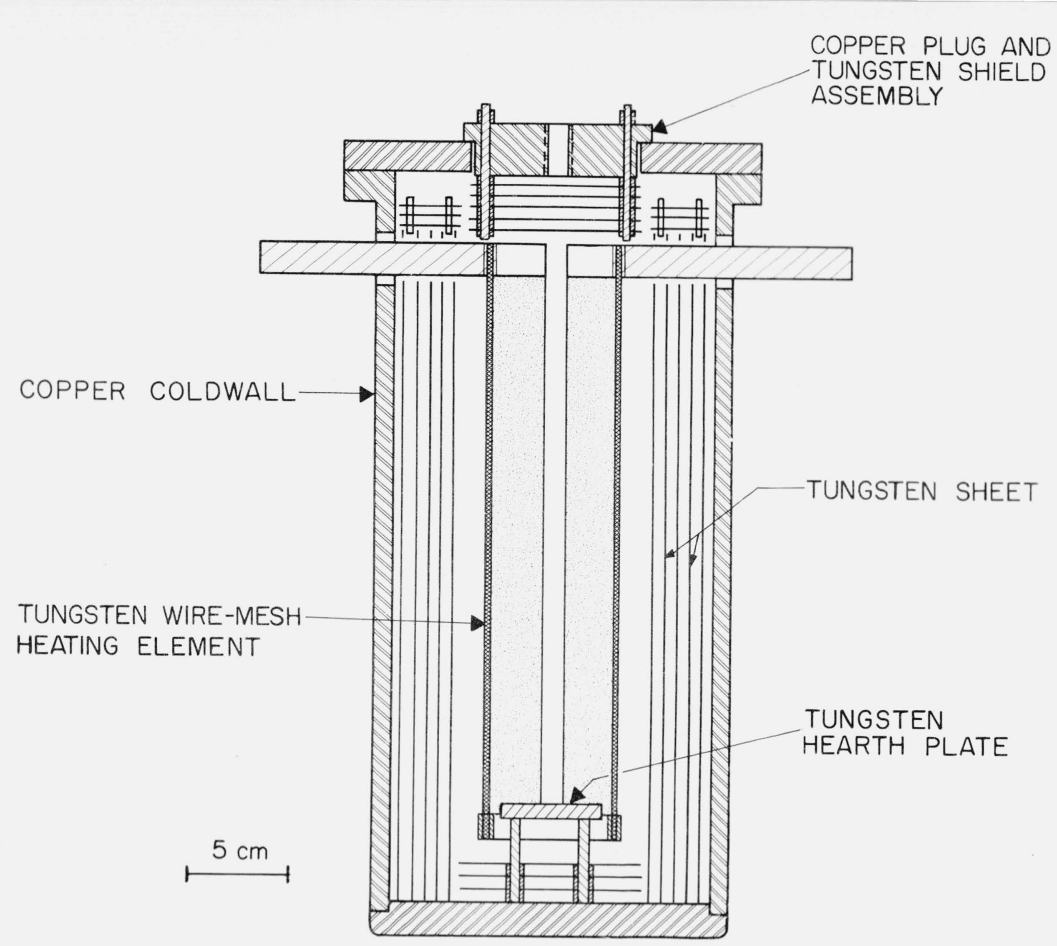

Figure 2. Coldwall assembly and hot-zone of ultra-high-vacuum, high-temperature furnace. The copper tubing for water cooling of the coldwall is not shown.

emf-temperature relationship of the thermoelements ${ }^{5}$ due to exposure. The error in the measurement of the relative changes by this procedure results primarily from: (a) the thermoelectric nonuniformity of the particular spool (lot) of wire; (b) the uncertainty in the measurement of the temperature; and (c) changes in the unheated "as received" thermoelement (and perhaps also the test thermoelement) that occur during the measurement of the emf-temperature relationship. In most cases, the contribution of (b) ${ }^{6}$ and (c) to the overall uncertainty in the measurement can be shown to be small in comparison to the contribution of (a). The contribution of (a) was estimated from checks on the thermoelectric uniformity of each spool of wire. Based upon these checks and a reasonable estimate for the contribution of (b) and (c), the maximum uncertainty in the measurement of the relative change in the thermal emf of the test thermoelements is estimated to be $\pm 20 \mu \mathrm{V}$ at $1273 \mathrm{~K}$, and $\pm 30 \mu \mathrm{V}$ at $2073 \mathrm{~K}$. However, for the thermoelements exposed at $2400 \mathrm{~K}$ and above in vacuum, the contribution of (b) is more significant. This occurs not because of a larger uncertainty in the meaurement of the temperature (it remains about the same), but rather because the thermoelectric power of the test thermoelement versus the unheated "as received" thermoelement is often substantially larger. In these cases, the maximum uncertainty in the measurements is then estimated to be $\pm 30 \mu \mathrm{V}$ at $1273 \mathrm{~K}$, and $\pm 50 \mu \mathrm{V}$ at $2073 \mathrm{~K}$.

The change in the thermal emf-temperature relationship of a composite thermocouple in which both thermoelements have been exposed in the above manner may be obtained by combining the changes measured for the separately exposed thermoelements. It is convenient to express the change in thermal emf of the thermoelements and thermocouples at a given temperature in terms of an equivalent temperature change $(\Delta T)$. We shall use the following convention in this paper: For the thermocouple, $\Delta T$ is obtained by dividing the change in the thermal emf of the thermocouple at a given temperature by the thermoelectric power $(d E / d T)$ of the thermocouple at the same temperature; $\Delta T$ for the separate thermoelements is obtained similarly, except that for the W-25 percent Re thermoelement (negative element of thermocouple), a negative value for the thermoelectric power of the thermocouple is used, so that a positive change in emf results in a negative $\Delta T$. In this manner, changes occurring in the separate thermoelements are expressed in terms of their effect upon the thermocouple, and the algebraic sum of the $\Delta T$ 's for each of the thermoelements equals the $\Delta T$ for the for the thermocouple.

\subsection{Investigation of Insulator-Thermoelements and Insulator-Sheath Interactions, Sheath Integrity and Thermocouple Sensor Performance}

An ultra-high-vacuum, high-temperature furnace system ${ }^{7}$ is being used in these investigations. The furnace system incorporates many of the features of present day vacuum technology. All metal and metal-to-ceramic construction is utilized throughout, and all components are capable of sustaining repeated and extended bakeouts at

\footnotetext{
5 The change in the emf-temperature relationship of a thermoelement is defined as the emf-temperature relationship of a thermocouple comprised of the thermo. element versus an unheated "as received" thermoelement from the same spool (lot) of wire, when the reference junctions are maintained at $273.15 \mathrm{~K}$ and the unheated "as received" thermoelement is designated as the negative leg of the thermocouple. ${ }^{6}$ Given by the product of the uncertainty in the measurement of the temperature and the thermoelectric power of the test thermoelement versus the unheated "as received" thermoelement.

7 Built commercially to NBS specifications.
} 
$525 \mathrm{~K}$ without damage or loss of vacuum integrity. A high-speed, ultra-high-vacuum pumping system is employed, and facilitates rapid attainment of ultra-clean environments. Some of the principal features of the furnace are illustrated in figures 2 and 3 . The furnace has a tungsten wire-mesh heating element $6.4 \mathrm{~cm}$ in diameter by $30.5 \mathrm{~cm}$ long, oriented with its central axis vertical. It is of single-phase design, having two semicylindrical tungsten wire-mesh segments that are connected at the bottom through a tungsten ring. Except at the bottom, the two segments are separated by a space of about $12 \mathrm{~mm}$. The heating element is surrounded by tungsten radiation shields formed from $0.125 \mathrm{~mm}$ thick tungsten sheet. The heating element and shields are enclosed within a watercooled copper coldwall assembly as shown in figure 2 . The coldwall assembly is mounted within a stainless steel vacuum chamber $(46 \mathrm{~cm}$ in diameter by $78 \mathrm{~cm}$ high), which is also water-cooled.

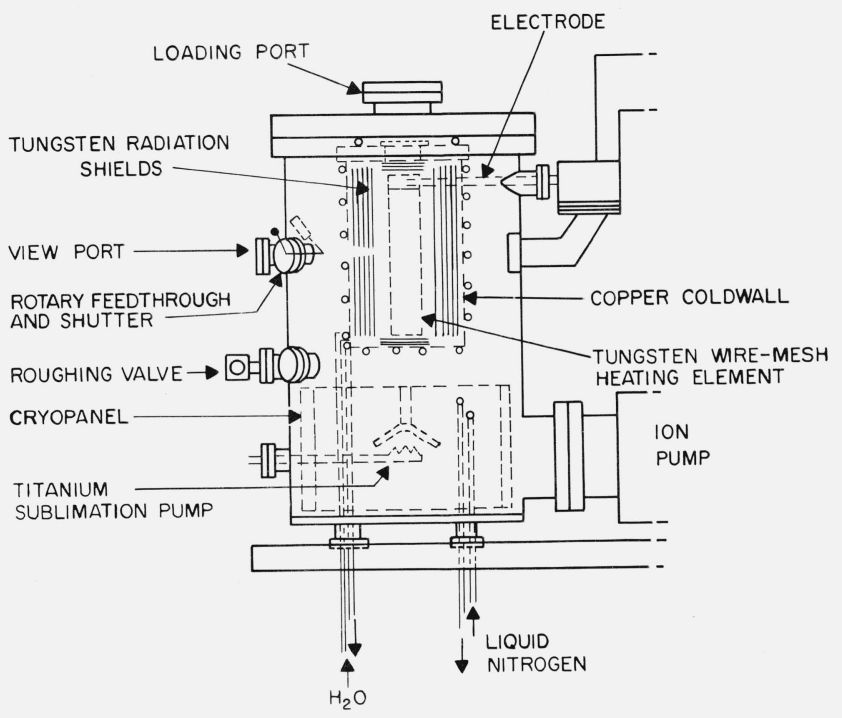

Figure 3. Principal features of ultra-high-vacuum, high-temperature furnace.

The roughing system, water cooling of stainless steel vacuum chamber, bakeout heaters and shroud, gas manifold, partial pressure gas analyzer, and ionization gage are not shown.

The portion of the copper coldwall and radiation shields directly above the heating element is removable through a $10 \mathrm{~cm}$ diam port at the top of vacuum chamber, thus providing complete access to the interior of the heating element for installing materials and experimental devices for test. An optical path is provided through the wiremesh heating element, side radiation shields, and copper coldwall for viewing the interior of the heating element through a $3.8 \mathrm{~cm}$ diam viewing port on the side of the vacuum chamber. The view port is equipped with a Corning Type 7056 glass window. A stainless steel shutter within the vacuum chamber fully covers the view port when closed and does not obscure any part of the port when open. The shutter is actuated by a direct-drive rotary-motion feedthrough that is mounted on the vacuum chamber adjacent to the view port. Electrical connections between the heating element and a power transformer are made through two water-cooled, metal-ceramic sealed elec- trodes that extend into the chamber through ports on the vacuum chamber. The electrodes also serve to support the wire mesh heating element and maintain its electrical isolation from the tungsten shields and copper coldwall.

A sorption pump roughing system and a high speed, ultra-high-vacuum pumping system are used to evacuate the vacuum chamber. The roughing system, consisting of three molecular sieve type sorption pumps mounted on a stainless steel manifold, is connected to the vacuum chamber through a $3.8 \mathrm{~cm}$ bakeable metal-sealed valve. The high-speed, high-vacuum pumping system consists of a 4.00 liter/s sputter ion pump and an accessory (three filament cartridge type) titanium sublimation pump (TSP).

A cylindrical stainless steel shroud (cryopanel), cooled with liquid nitrogen, surrounds the TSP and enhances pumping. An optically-dense baffle is installed above the TSP and shields the upper chamber region from titanium deposition. The pressure within the chamber is measured with a nude Bayard-Alpert type ionization gauge. For bakeout, ceramic-insulated metal-clad heaters are attached to the exterior walls of the vacuum chamber and ion pump; these systems are surrounded by an aluminum bakeout shroud. The bakeout heater power controls are interlocked electrically with pressure and temperature sensing controls and permit unattended (automatic) bakeout of the chamber and ion pump at $525 \mathrm{~K}$. To aid in studies of vacuum degassing of materials, a partial pressure gas analyzer is mounted on the side of the vacuum chamber. It is a cycloidal analyzer, using a crossed electrostatic and magnetic field, and is capable of mass number identifications from 2 to 100 atomic mass units (amu) down to pressures of $5 \times 10^{-12}$ torr.

If, after evacuating and baking the system, a gaseous environment is desired, high purity gas from a cylinder of compressed gas is introduced through a stainless steel manifold that is connected to the vacuum chamber by a $1 \mathrm{~cm}$ bakeable all-metal valve. The manifold is of design similar to that of the one described in section 2.1.

Power to the wire-mesh heating element is supplied through a 67-kVA Silicon Controlled Rectifier (SCR) type proportional power controller and a 47-kVA air-cooled stepdown transformer. Input line voltage to the power controller is $480 \mathrm{~V}, 60 \mathrm{~Hz}$, single phase. The temperature within the hot zone is controlled by the indirect method of controlling the power supplied to the mesh heating element.

For automatically controlling the power at the desired level (set point), a closed loop control system is provided. The closed loop control utilizes a thermal watt converter type power sensor, which in conjunction with a highresponse electronic controller, feeds back an appropriate control signal to the SCR proportional power controller. An adjustable set point on the electronic controller permits selecting a power level with a resolution of better than 0.1 percent. The controller has a $20 \mathrm{~ms}$ response and includes features such as adjustable gain, rate and reset time controls. At maximum gain settings, the control system has a sensitivity equivalent to about $2 \mathrm{~W}$. The power controls are electrically interlocked with other controls and automatically shut off the heating element power if the cooling water flow drops below a safe operating level or if the pressure in the vacuum chamber rises above 
an adjustable preset value. In certain applications, it may be advantageous to control directly the furnace hot-zone temperature by utilizing the output of a thermocouple sensor or an automatic photoelectric pyrometer. This type of control is also possible if minor modifications to the input circuitry of the electronic controller are made.

When the furnace is at ambient temperature (no power), base pressures of less than $5 \times 10^{-11}$ torr may be achieved within $20 \mathrm{~h}$, (including a $10 \mathrm{~h}$ bakeout of the chamber and the pumping system at $525 \mathrm{~K}$ ). The furnace is designed to produce hot-zone temperatures to $3000 \mathrm{~K}$ while maintaining the pressure in the $10^{-8}$ torr range; when the furnace chamber is filled with a high-purity inert gas or hydrogen gas at a pressure at 1 atm, it is designed to produce hot-zone temperatures in excess of $2700 \mathrm{~K}$.

At elevated temperatures, the temperature in the hotzone of the furnace responds very rapidly to changes in heating element power. Hence, precise automatic control of the power provides a reasonably sensitive and reproducible method for controlling the hot-zone temperature. With the furnace chamber filled with $1 \mathrm{~atm}$ pressure of argon, a temperature stability - over a period of $1000 \mathrm{~h}$ - of $\pm 4 \mathrm{~K}$ at $2073 \mathrm{~K}$ has been achieved. Over a $24 \mathrm{~h}$ period, the temperature stability has been typically $\pm 2 \mathrm{~K}$ at $2073 \mathrm{~K}$, and for shorter periods (20 to $30 \mathrm{~min})$, \pm 0.5 K. Temperature stability was ascertained from measurements made with an automatic photoelectric optical pyrometer and with W-3 percent Re versus W-25 percent Re thermocouples.

The furnace is presently being used for vacuum degassing of materials, insulator - W/Re wire interaction studies in argon, and testing and evaluating the performance of $\mathrm{BeO}$ insulated thermocouples. For vacuum degassing and processing of sintered $\mathrm{BeO}$ tubing, the insulating parts have been supported in the hot-zone of the furnace with a W-Re wire basket that was formed by interweaving 0.125 and $0.25 \mathrm{~mm}$ diam wires. Studies of the chemical behavior of $\mathrm{W}$-Re thermocouple wire that is insulated with sintered $\mathrm{BeO}$ insulating tubing are being performed in high purity argon $(<10 \mathrm{ppmv}$ total impurities) at about $1 \mathrm{~atm}$ pressure and temperatures in the 2000 to $2400 \mathrm{~K}$ range. For these studies, W-3 percent Re and $\mathrm{W}-25$ percent Re wires of $0.25 \mathrm{~mm}$ diam are inserted into degassed, sintered, double-bore $\mathrm{BeO}$ insulating tubing of $0.3 \mathrm{~mm}$ bore and $1.1 \mathrm{~mm}$ o.d. The insulated wire is then suspended from the top shield assembly for exposure in the hot-zone of the furnace.

For testing and evaluating the performance of $\mathrm{BeO}$ insulated W-Re type thermocouples, a tantalum blackbody enclosure is suspended in the hot-zone of the furnace. One design that has been used successfully in the 1800 to 2400 $\mathrm{K}$ range is shown in figure 4 . The cylindrical tantalum enclosure is $2.5 \mathrm{~cm}$ in diam by $8 \mathrm{~cm}$ long, and has a $0.5 \mathrm{~mm}$ thick wall and a $1 \mathrm{~mm}$ diam blackbody opening. It is supported within the furnace hot-zone by a $6.35 \mathrm{~mm}$ diam tantalum tube that is attached (heli-arc welded) to the top shield assembly. This design closely approximates an ideal blackbody if the walls of the enclosure are at a uniform temperature. Using calculations derived by DeVos [7], it is estimated that the effective emittance of this blackbody enclosure is greater than 0.997 .

Thermocouples for test are inserted through the 6.35

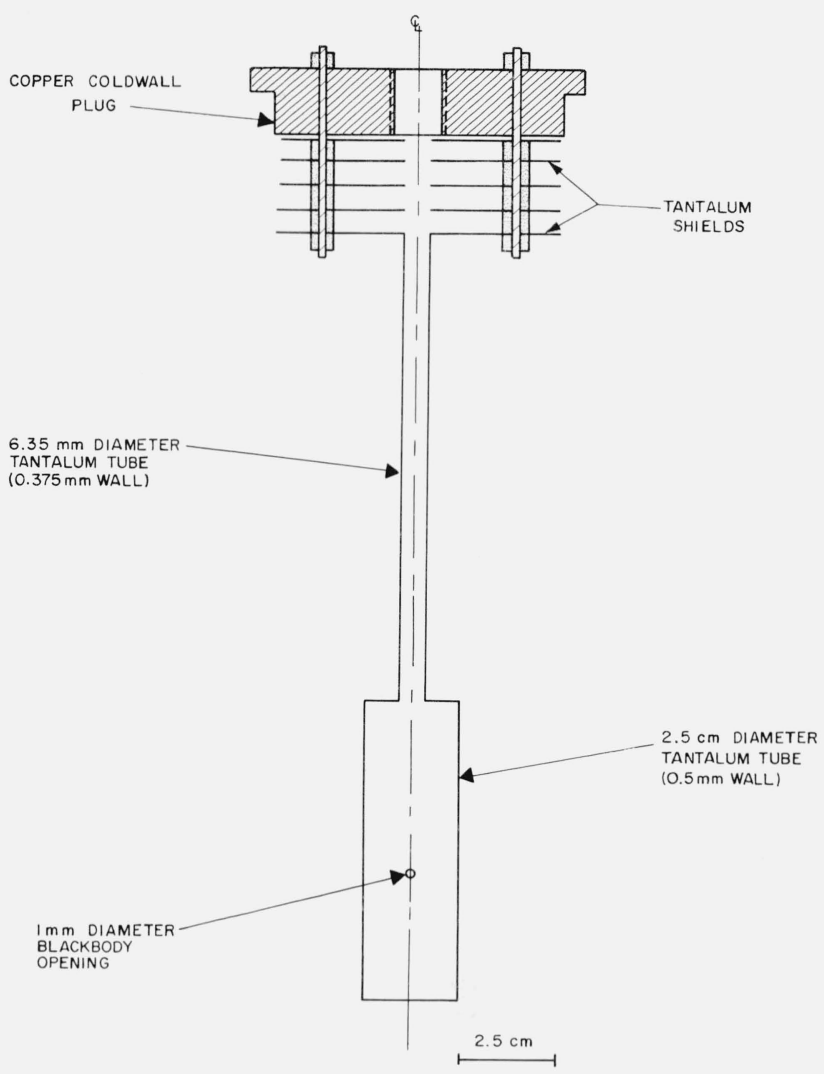

FigURE 4. Tantalum blackbody enclosure for high-temperature furnace.

$\mathrm{mm}$ diam tantalum supporting tube so that their measuring junctions are within the blackbody enclosure. The thermocouple wires lead out of the vacuum chamber through metal-glass feedthroughs at the top of the chamber and the wire exits are sealed with a solvent-free epoxy resin. The metal-glass feedthroughs are mounted on a $15 \mathrm{~cm}$ o.d. ultra-high-vacuum flange that seals to a mating flange on the $10 \mathrm{~cm}$ diam loading port.

The temperature of the tantalum blackbody enclosure is determined with a visual optical pyrometer, and also with an automatic photoelectric pyrometer by sighting on the blackbody opening. The pyrometers used in this work are of commercial design and are calibrated ${ }^{8}$ by relating the pyrometer lamp current to the brightness or blackbody temperature. In use, the pyrometer lamp current is determined by measuring the voltage drop across a $1 \Omega$ standard resistor in series with the lamp. All voltage measurements, including the emf's of test thermocouples, are made with a precision potentiometer having a limit of error of less than $\pm(0.015 \%$ of reading $\pm 2 \mu \mathrm{V})$, or alternatively with a 6 digit digital voltmeter having an absolute voltage accuracy of $( \pm 0.004 \%$ of reading $\pm 2 \mu \mathrm{V})$.

Thus far more than $1200 \mathrm{~h}$ of reliable operation in the 1800 to $2400 \mathrm{~K}$ range has been accumulated with the Ta blackbody in an argon environment. Two sets of measurements have been made (in an argon atmosphere) with three W-3 percent Re versus W-25 percent Re thermo-

8 Calibration performed by Radiation Thermometry Section at NBS. See NBS Monograph 41 for calibration procedure. 
couples inserted at different immersion depths in the blackbody enclosure. Different thermocouples were used for each set of measurements. The measurements indicate that the vertical temperature distribution over the central 5 centimeters of the blackbody enclosure is uniform to within about 2 kelvins at temperatures above $1800 \mathrm{~K}$. Below $1800 \mathrm{~K}$ the temperature distribution becomes progressively less uniform, and at $1300 \mathrm{~K}$ a temperature gradient of about $2 \mathrm{~K} / \mathrm{cm}$ exists over the central 5 centimeters of the enclosure. The improved temperature uniformity at high temperatures is apparently a result of the increasing predominance of the radiative heat flux in the system as the temperature is increased.

\section{Results and Discussion}

\subsection{Studies Completed}

Studies on the effects of thermal exposure of bare 0.25 mm diam W-3 percent Re and W-25 percent Re thermoelements in environments of vacuum, argon and hydrogen have been completed [8]. In these studies, thermoelements were exposed for periods ranging from 1 to $1000 \mathrm{~h}$ at 2400 $\mathrm{K}$ in high vacuum $\left(<1 \times 10^{-8}\right.$ torr $)$ and in high purity argon and hydrogen environments (at $1 \mathrm{~atm}$ ). Some tests in vacuum at 2200 and $2600 \mathrm{~K}$ were also conducted.

In the argon and hydrogen environments, both thermoelements typically experienced a change (shift) in their emf-temperature relationship during the first hour of exposure at $2400 \mathrm{~K}$. Subsequent exposure for periods up to $1000 \mathrm{~h}$ was found to produce no further significant changes (drift) in the emf-temperature relationship. Typical curves showing the change in the emf-temperature relationship of $\mathbb{W}-3$ percent $\mathrm{Re}$ and $\mathrm{W}-25$ percent Re thermoelements after exposure in argon at $2400 \mathrm{~K}$ for periods of $1,50,100,250,500,750$, and $1000 \mathrm{~h}$ are given in figure 5 . The changes all fell within the shaded region, and no trend of the data with increasing exposure time was apparent. Similar results were obtained with thermoelements from the same wire lots after being exposed in hydrogen at $2400 \mathrm{~K}$, except that the shift in the emftemperature relationship of $\mathrm{W}-3$ percent Re thermoelement averaged slightly less (about $120 \mu \mathrm{V}$ at $2073 \mathrm{~K}$ ). In the case of W-25 percent Re thermoelement there was no discernible difference between the argon and hydrogen results.

Three different lots of $0.25 \mathrm{~mm}$ diam W-3 percent Re

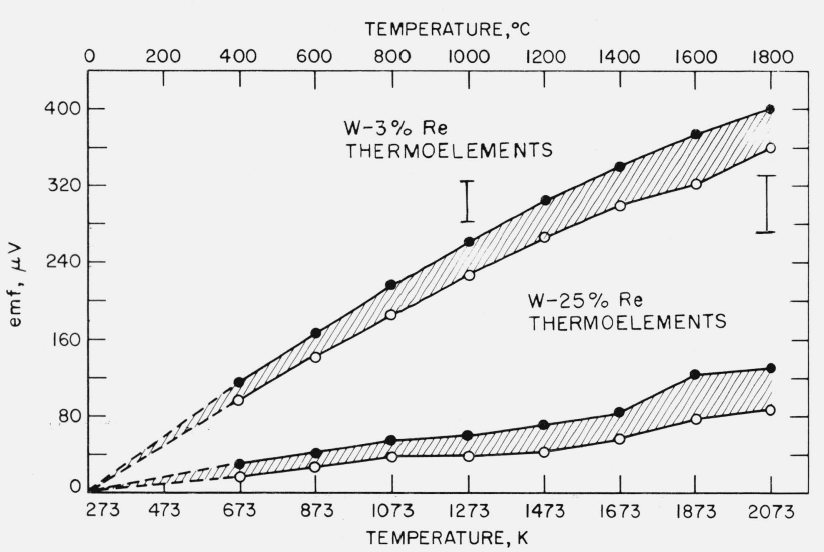

Figure 5. Change in the emf-temperature relationship of $W-3 \%$ Re and $W-25 \%$ Re thermoelements from one lot after exposure in argon at $2400 \mathrm{~K}$ for periods up to $1000 \mathrm{hrs}$.

Shaded region indicates range of values obtained for thermoelements exposed for $1,50,100,250,500,750$, and 1000 hours. Bars designate the estimated uncertainty in measurements at the indicated temperature.

versus W-25 percent Re thermocouple wires from the same supplier have been examined thus far, and the magnitude of the initial shift in the thermal emf varies somewhat between lots. Table 1 gives the changes in the emftemperature relationship (equivalent $\Delta T$ ) at $2073 \mathrm{~K}$ for the thermoelements and thermocouples from the three lots after thermal exposure in argon for 1 and $50 \mathrm{~h}$ at $2400 \mathrm{~K}$. It is noted that the shift for all lots is essentially complete after an exposure for $1 \mathrm{~h}$. Further, the thermocouples from the three different lots exhibit positive shifts equivalent to about 0.1 percent, 0.3 percent, and 1 percent at $2073 \mathrm{~K}$.

It is well known that commercial W-Re thermocouple materials will experience some shift in their emftemperature relationship on initial heating to elevated temperatures $[5,9]$. However, these results clearly demonstrate that thermocouple wire can be supplied which will exhibit only a very small initial shift $(0.1 \%$ to $0.2 \%)$. As with most W-Re thermocouple wire sold in this country, the thermocouple materials used in this work were thermally conditioned by the supplier with a heat treatment that tends to minimize the shift and yet retain desirable mechanical properties.

Many engineering applications require that temperature be measured with an accuracy of only a few percent. For these applications, the shift in the "as supplied" wire is

TABLE 1. Average change in the emf-temperature relationship (equivalent $\Delta \mathrm{T}$ ) at $2073 \mathrm{~K}$ of the thermoelements and thermocouples from three different lots after exposure at $2400 \mathrm{~K}$ in argon (1 atm)

$\Delta \mathrm{T}$ in Kelvins

\begin{tabular}{|c|c|c|c|c|c|c|c|c|c|}
\hline \multirow[b]{2}{*}{$\begin{array}{c}\text { Exposure Time } \\
\text { (Hours) }\end{array}$} & \multicolumn{3}{|c|}{ Lot 1} & \multicolumn{3}{|c|}{ Lot 2} & \multicolumn{3}{|c|}{ Lot 3} \\
\hline & $\begin{array}{l}\text { W }-3 \% \text { Re } \\
\text { Element }\end{array}$ & $\begin{array}{c}\text { W-25\% Re } \\
\text { Element }\end{array}$ & $\begin{array}{l}\text { Thermo- } \\
\text { couple }\end{array}$ & $\begin{array}{l}\mathrm{W}-3 \% \mathrm{Re} \\
\text { Element }\end{array}$ & $\begin{array}{l}\text { W }-25 \% \mathrm{Re} \\
\text { Element }\end{array}$ & $\begin{array}{l}\text { Thermo- } \\
\text { couple }\end{array}$ & $\begin{array}{l}\text { W }-3 \% \text { Re } \\
\text { Element }\end{array}$ & $\begin{array}{l}\text { W-25\% Re } \\
\text { Element }\end{array}$ & $\begin{array}{l}\text { Thermo- } \\
\text { couple }\end{array}$ \\
\hline 1 & +6 & -4 & +2 & +23 & -5 & +18 & +9 & -3 & +6 \\
\hline 50 & +7 & -4 & +3 & +24 & -7 & +17 & +8 & -2 & +6 \\
\hline
\end{tabular}


sufficiently small so that its effects may be neglected, and no special aging of the wire by the user is necessary. Furthermore, in typical thermocouple applications, high temperature exposure of the thermocouple will result in thermocouple wire that is not fully thermally conditioned along its entire length. For a given wire lot, the shift would then, in general, be less than the shift reported here. Nevertheless, the occurrence of such shifts tends to restrict the accuracy obtainable. For those cases where the ultimate in performance and accuracy is desired, additional thermal aging to eliminate the shift will probably prove desirable. This can be accomplished in such a manner that afterwards, the wires will possess sufficient room temperature ductility for fabrication purposes. Closer control of the thermal conditioning process in order to minimize the shift in the "as supplied" wire has been recently reported by one supplier [10].

Exposure of the bare thermoelements in high vacuum $\left(<1 \times 10^{-8}\right.$ torr $)$ at temperatures above $2200 \mathrm{~K}$ results in a continual change (drift) in their emf-temperature relationship. Changes that occurred in the emftemperature relationship of the thermoelements after exposure for periods of 50,250 , and $500 \mathrm{~h}$ at $2400 \mathrm{~K}$ are given in figures 6 and 7 . The drift in the emf-temperature relationship of the thermoelements in high vacuum is strongly dependent upon the temperature of exposure. At $2600 \mathrm{~K}$, an exposure of only $50 \mathrm{~h}$ produces about the same drift as an exposure of $500 \mathrm{~h}$ at $2400 \mathrm{~K}$, while at $2200 \mathrm{~K}$ the drift after exposure for $500 \mathrm{~h}$ is negligible.

The drift in the emf-temperature relationship of both thermoelements in high vacuum has been shown to be the result of a preferential loss of Re from the alloys by evaporation. This was confirmed by electron probe microanalysis of the exposed thermoelements. Hence, any processing of the bare thermoelements in vacuum should be confined to temperatures of $2200 \mathrm{~K}$ or below to avoid changes in alloy composition. Furthermore, bare-wire

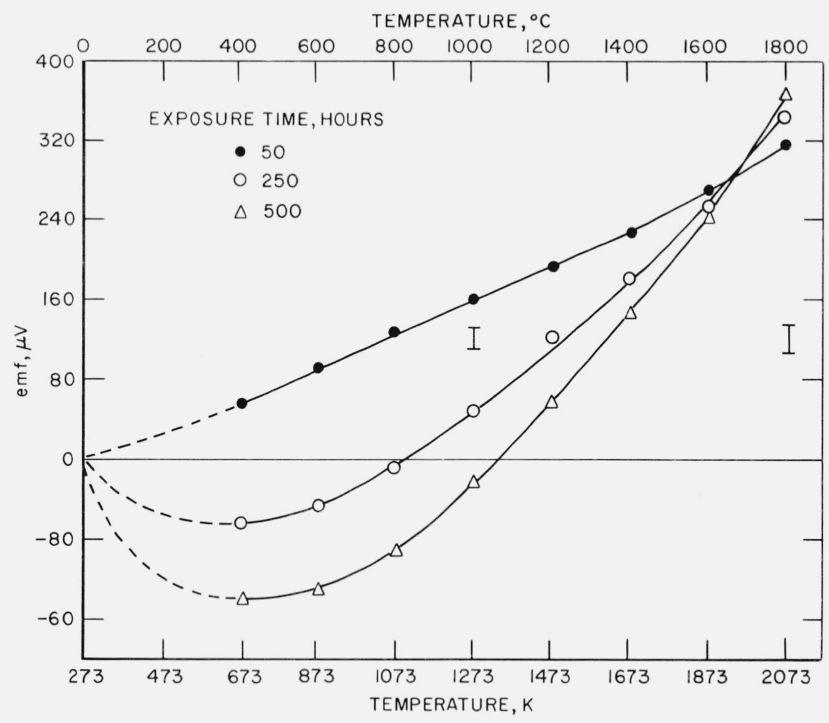

Figure 6. Change in the emf-temperature relationship of $W-3 \%$ Re thermoelements from one lot after thermal exposure for 50 , 250 , and 500 h at $2400 \mathrm{~K}$ in vacuum $\left(<1 \times 10^{-8}\right.$ torr $)$.

Bars designate the estimated uncertainty in measurements at the indicated tem. perature.

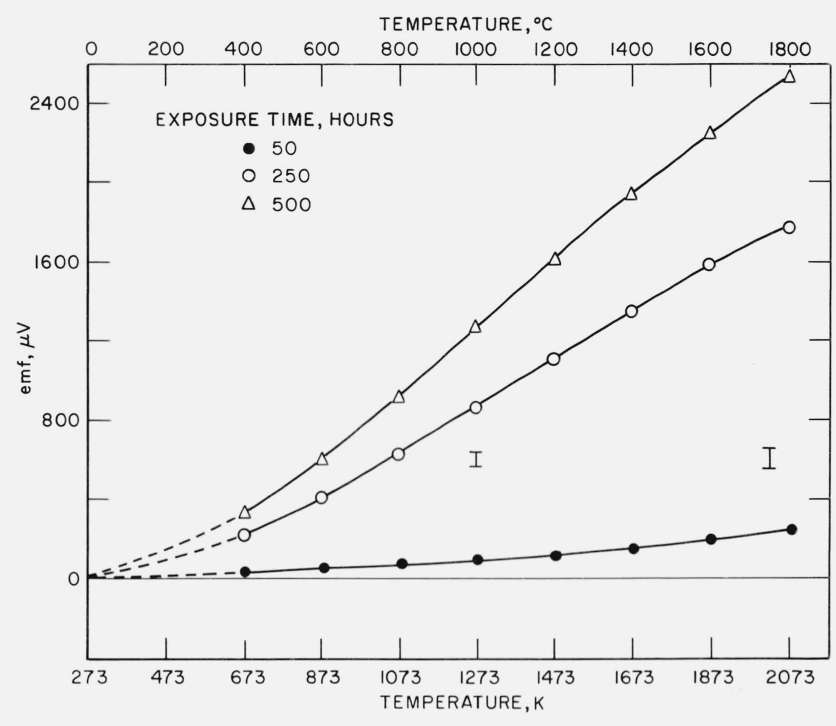

Figure 7. Change in emf-temperature relationship of $W-25 \% R e$ thermoelements from one lot after thermal exposure for 50, 250, and $500 \mathrm{~h}$ at $2400 \mathrm{~K}$ in vacuum $\left(<1 \times 10^{-8}\right.$ torr $)$.

Bars designate the estimated uncertainty in measurements at the indicated tem. perature.

W-3 percent Re versus W-25 percent Re thermocouples could be expected to drift in calibration with use in high vacuum at temperatures above $2200 \mathrm{~K}$. However, since the conditions and methods of exposure for thermocouples in actual use are different from those in the present studies, the results presented are only considered as indicative of expected material behavior and are not generally valid for predicting the magnitude of the drift for thermocouples in actual use. These results indicate that the thermal emf of a bare-wire thermocouple will decrease with exposure in high vacuum at $2400 \mathrm{~K}$ or above, due primarily to the preferential loss of Re from the W-25 percent Re thermoelement. At $2400 \mathrm{~K}$, the rate of change in the calibration might typically be on the order of a few tenths kelvin per hour.

\subsection{Current and Planned Studies}

Work now in progress includes studies to establish suitable time-temperature parameters for thermally conditioning $\mathrm{W}-3$ percent Re and $\mathrm{W}-25$ percent Re thermocouple wire before use. Tests to evaluate the bare thermoelements in high purity helium and nitrogen environments at $2400 \mathrm{~K}$ are also being performed. In addition, the behavior and performance of other commercially available W-Re type thermocouples (W-5\% Re versus W-26\% Re and $\mathrm{W}$ versus $\mathrm{W}-26 \% \mathrm{Re}$ ) are being investigated.

In progress also are studies with high purity $(>99.8 \%)$ sintered double-bore beryllium oxide insulating tubing in the 2000 to $2400 \mathrm{~K}$ range. Preliminary results have indicated that material transport from the W-Re thermoelements to the inner bore of $\mathrm{BeO}$ tubing may occur in a high purity argon environment if the insulating tubing is not well degassed prior to use. In some cases, poor degassing technique has resulted in chemical reactions between the $\mathrm{BeO}$ and W-Re thermoelements. However, there are indications that, if the $\mathrm{BeO}$ insulating tubing is 
first well degassed, the insulator-thermoelement material incompatibility problems will be negligible during subsequent use in high purity inert environments in the temperature range of interest. Tests are in progress with $\mathrm{BeO}$ insulated W-3 percent Re versus W-25 percent Re thermocouples in argon to establish the long term stability and behavior of this combination. The results of these studies will be reported in subsequent papers.

Studies will begin within the next year to evaluate Ta sheath performance, sheath-BeO insulator interactions, and the capabilities and behavior of fully sheathed thermocouple sensors.

\section{References}

[1] Sandefur, N. L., Carpenter, F. D., Grenda, R. J., and Steibel, J. S., Reliability of high temperature thermocouples in irradiation capsules, National Symposium on Developments in Irradiation Testing Technology (Conf-690910), Sandusky, Ohio, Sept. 9-11, 1969, pp. 551-582.

[2] Heckelman, J. D., A retractable-replaceable thermocouple for in-pile experiments, National Symposium on Developments in Irradiation in Irradiation Testing Technology (Conf690910), Sandusky, Ohio, Sept. 9-11, 1969, pp. 652-668.

[3] Schwarzer, D. E., High temperature thermal cycling drift test of $\mathrm{W}_{95}-\mathrm{Re}_{5}$ versus $\mathrm{W}_{74}-\mathrm{Re}_{26}$ thermocouples, National Symposium on Developments in Irradiation Testing Technology. (Conf-690910), Sandusky, Ohio, Sept. 9-11, 1969, pp. 307-329.
[4] Droege, J. W., Miller, N. E., Schimek, M. E., Wood, V. E., and Ward, J. J., Refractory metal thermocouples in nuclear and high-temperature applications, Report No. BMI-X10246, Battelle Memorial Institute, Columbus, Ohio (November, 1968).

[5] Walker, B. E., Ewing, C. T., and Miller, R. R., Instability of refractory metal thermocouples, Rev. of Sci. Instr. 36 No. 6, 816-825 (June, 1965).

[6] Thomas, D. B., A furnace for thermocouple calibrations to $2200{ }^{\circ}$ C, J. Res. Nat. Bur. Stand. (U.S.), 66C (Eng. and Instr.), No. 3, 255-260 (July-Sept., 1962).

[7] DeVos, J. C., Evaluation of the quality of a blackbody, Physica XX, No. 10, 669-689 (Oct. 1954).

[8] Burns, G. W., and Hurst, W. S., An investigation of W-3\% Re and W-25\% Re thermoelements in vacuum, argon and hydrogen, Report No. NASA CR-72639, National Aeronautics and Space Administration, Cleveland, Ohio (March, 1970).

[9] Hall, Jr., B. F., and Spooner, N. F., Application and performance data for tungsten-rhenium alloy thermocouples, National Aeronautic and Space Engineering and Manufacturing Meeting, Los Angeles, Calif., Sept. 23-27, 1963, Paper 750C (Society of Automotive Engineers, Inc., New York, N. Y.)

[10] Tseng, Y., Schnatz, S., Zysk, E. D., Tungsten 3 rhenium vs tungsten 25 rhenium thermocouple-some recent developments, Engelhard Industries Technical Bulletin XI, No. 1, 12-18 (June, 1970).

(Paper 75C2-319) 